\title{
Factors influencing the outcome of image-guided percutaneous drainage of intra-abdominal abscess after gastrointestinal surgery
}

\author{
Yoshiki Okita • Yasuhiko Mohri • Minako Kobayashi · Toshimitsu Araki • \\ Koji Tanaka • Yasuhiro Inoue $\cdot$ Keiichi Uchida $\cdot$ Koichiro Yamakado • \\ Kan Takeda $\cdot$ Masato Kusunoki
}

Received: 16 February 2012/ Accepted: 19 July 2012/Published online: 14 February 2013

(C) The Author(s) 2013. This article is published with open access at Springerlink.com

\begin{abstract}
Purpose To improve the selection of patients for percutaneous abscess drainage (PAD) to treat postoperative intra-abdominal abscess after gastrointestinal surgery, we investigated the factors predictive of outcome.

Methods Of 143 consecutive patients with symptomatic postoperative intra-abdominal abscess after a gastrointestinal tract resection, 104 who underwent image-guided PAD as the initial treatment were reviewed. We assessed the possible associations between successful PAD and patient-, abscess-, surgical-, and drainage-related variables, and investigated the success rates of PAD for patients with vs. those without the factors related to successful outcome. Results Based on monitoring for 1 year after PAD, the success rate of this procedure was $85.6 \%$ (89/104). Multivariate analysis revealed that the interval between surgery and the onset of abscess $(p=0.0234)$ and a single abscess $(p=0.0038)$ were independently associated with a successful outcome. Single late-onset abscess resolved completely within 10 weeks in $91.4 \%$ of these patients.

Conclusions Despite new strategies aimed at preventing surgical site infection, PAD remains an important factor in the postoperative management of gastrointestinal surgery in Japan. Initial recognition of the day of onset and the number of abscesses are important prognostic factors.
\end{abstract}

Y. Okita $(\bowtie) \cdot$ Y. Mohri · M. Kobayashi · T. Araki ·

K. Tanaka $\cdot$ Y. Inoue $\cdot$ K. Uchida $\cdot$ M. Kusunoki

Departments of Gastrointestinal and Pediatric Surgery,

Mie University Graduate School of Medicine,

2-174 Edobashi, Tsu, Mie 514-8507, Japan

e-mail: nyokkin@clin.medic.mie-u.ac.jp

K. Yamakado $\cdot$ K. Takeda

Department of Radiology, Mie University Graduate School

of Medicine, 2-174 Edobashi, Tsu, Mie 514-8507, Japan
Keywords Postoperative intra-abdominal abscess . Percutaneous abscess drainage $\cdot$ CT-guided drainage

\section{Introduction}

Intra-abdominal abscess is a frequent cause of morbidity and mortality following surgery of the alimentary tract $[1,2]$. In the past three decades, advances in image-guided percutaneous abscess drainage (PAD) have provided a safe and effective alternative to surgical drainage [3-7]. Despite the lack of randomized studies comparing percutaneous to surgical drainage, PAD has become a widely accepted treatment for accessible postoperative intra-abdominal abscess, especially in Western countries [8-12]. However, the concepts of treatment for postoperative intra-abdominal abscess after gastrointestinal surgery differ between Japan and Western countries [13]. In Japan, routine abdominal drains are generally placed to facilitate the diagnosis of anastomotic leakage and reduce the risk of intra-abdominal abscess formation [14, 15], although increasing evidence suggests that prophylactic drains do not reduce the incidence of postoperative complications following a variety of intra-abdominal procedures [16]. Routine abdominal drains also play a therapeutic role when intra-abdominal abscess develops after surgery [13]. However, with the increasing use of CT-guided drainage, the indications for PAD have expanded.

The current study focuses on how patient-, surgery-, abscess- and drainage-related factors affect the outcome of PAD, since the implementation of standard surgical site infection prevention policies in Japan. We investigated the effectiveness and safety of PAD, and identified the factors predictive of its successful outcome, to improve the selection of patients who would benefit from this procedure 
for postoperative intra-abdominal abscess following gastrointestinal surgery.

\section{Methods}

Patients

Our surgical site infection database identified 143 patients with a symptomatic postoperative intra-abdominal abscess diagnosed after gastrointestinal surgery, between January 2002 and March 2010, at Mie University Hospital. Among these, 104 patients received image-guided PAD as the initial treatment. The 39 patients who did not receive image-guided PAD initially were treated with open surgical drainage $(n=16)$, antibiotic therapy alone $(n=16)$, or transanal drainage $(n=7)$. The study group included 71 men and 33 women, with a mean age of $51 \pm 2$ years (mean \pm SE, range 14-91). The primary diseases and initial surgical procedures are summarized in Tables 1 and 2 , respectively. Gastrointestinal surgery was performed for malignant disease in $47(45.2 \%)$ patients and for inflammatory bowel disease in $41(39.4 \%)$ patients. Asymptomatic radiographical enteric fistulae without abscess were not included. Intra-abdominal abscess was suspected with the development of such symptoms as abdominal pain, pyrexia, leucocytosis, and shock. The abscess was diagnosed by CT scan in all cases and defined as an infected fluid collection identified by image-guided needle aspiration during image-guided PAD. Recurrent abscess after restorative surgery for previous postoperative intraabdominal abscess was excluded, so that patients were not included more than once. When severe diffuse peritonitis or septic shock was suspected, open surgical drainage was performed. Patients with an abscess that could not be treated by PAD, in the absence of signs of peritonitis, were treated with antibiotic therapy alone. Transanal drainage was performed for enteric fistula just above the anus, caused by anastomotic leakage after surgery such as low anterior resection, and when PAD carried a risk of injury to other abdominal organs or major vessels.

Indications and procedure for PAD to treat

postoperative intra-abdominal abscess

PAD was attempted as the initial procedure only if an abscess could be accessed without risk of injury to other abdominal organs, if severe diffuse peritonitis was not suspected, and in the absence of septic shock at presentation, based on judgment of the surgeon and interventional radiologist. All procedures were performed under local anesthesia and image guidance: as CT-guided PAD in 83 patients and as ultrasound-guided PAD in 21 patients. The
Table 1 Underlying primary disease

\begin{tabular}{lc}
\hline & $n$ \\
\hline Colorectal cancer & 28 \\
Ulcerative colitis & 24 \\
Gastric cancer & 19 \\
Crohn's disease & 17 \\
Colon diverticula & 4 \\
Acute appendicitis & 4 \\
Adhesive small bowel obstruction & 3 \\
Others & 5 \\
\hline
\end{tabular}

Table 2 Initial surgical procedures

\begin{tabular}{lr}
\hline & $n$ \\
\hline Gastric surgery & \\
Total gastrectomy & 10 \\
Distal gastrectomy & 8 \\
Small intestinal surgery & 11 \\
Small bowel resection & 11 \\
Ileostomy closure & 6 \\
Stoma construction & 3 \\
Ileoanal reanastomosis & 4 \\
Appendectomy & \\
Colorectal surgery & 13 \\
Rectal resection & 9 \\
Right hemicolectomy & 9 \\
Restorative proctocolectomy with ileal pouch anal anastomosis & 4 \\
Subtotal colectomy with ileorectal anastomosis & 4 \\
Left hemicolectomy & 4 \\
Subtotal colectomy without ileorectal anastomosis & 3 \\
Transverse colon resection & 3 \\
Sigmoidectomy & 2 \\
Ileocolorectal or colorectal anastomosis after Hartman's & 2 \\
procedure & 1 \\
Abdominal perineal resection & \\
Colostomy closure & \\
& \\
& \\
& \\
&
\end{tabular}

attending interventional radiologist decided on the size and number of catheters used, based on the nature of the fluid obtained at needle aspiration and the extent of the abscess. The catheter size ranged from 8 to $12 \mathrm{~F}$ and Pigtail drainage catheters (Skater Drainage Catheter; Angiotech, Stenlose, Denmark) were placed in the abscess cavity using the Trocar method or Seldinger technique. When abscess drainage was insufficient, the catheter was replaced by a thicker one, inserted using an over-the-guidewire technique or it was moved to a position that allowed sufficient drainage. Bags were attached for gravity drainage after placing a stopcock at the external end of the catheter for routine irrigation. Abscess cavities of all patients who 
underwent PAD were irrigated with natural saline from drainage tubes about 1 week after PAD. No concomitant antibiotics were given before puncture of the PAD and/or during PAD when the abscesses were localized with mild symptoms, based on the judgment of the surgeon. However, concomitant antibiotics were administered to patients with severe symptoms. Antibiotics were initially chosen empirically and changed, if necessary, based on culture and sensitivity results.

\section{Definition of outcomes}

Patients were divided into two groups depending on whether the PAD outcome was successful. Success was defined as complete resolution of the intra-abdominal abscess or enteric fistula after one or more PAD procedures without the need for surgery. Complete resolution of the intra-abdominal abscess was defined as radiological disappearance of the abscess cavity and clinical disappearance of the symptoms. The catheter was removed after CT or fluoroscopy confirmed complete resolution of the fluid collection or enteric fistula. When recurrent intraabdominal abscesses had been drained and resolved completely, the outcome of PAD was defined as successful. The "success group" did not include any patients in whom PAD was subsequently deemed to have failed in the follow-up period. Failure was defined as the need for elective interval surgery or emergency surgery after PAD. Patients with a postoperative intra-abdominal abscess were monitored for at least 1 year after PAD and their outcomes were judged according to the definitions of success and failure.

\section{Definition of variables}

The potential success factors were as follows

Patient-related factors age at surgery, gender, malignant disease, inflammatory bowel disease, steroid treatment, diabetes mellitus, and laboratory data just before PAD (white blood cell count, hemoglobin, CRP, ALB, choline esterase).

Surgery-related factors surgical procedure, stoma construction, anastomotic operation, surgical duration, operative blood loss, and wound class.

Abscess-related factors interval between surgery and onset, interval between onset and PAD, size and number of abscess/es.

Drainage-related factors drainage procedure, concomitant use of antibiotic therapy, duration of antibiotic therapy, multiple drains, and need for additional PAD.

The surgical procedure and wound class were categorized according to the National Nosocomial Infections Surveillance System. Surgical procedures were divided into gastric surgery (GAST), small bowel surgery (SB), appendectomy (APPY), and colorectal surgery (COLO). The wound class comprised four criteria: clean, cleancontaminated, contaminated, or dirty [17]. The day of onset was defined as the day when patients complained of symptoms related to the abscess. Common presenting symptoms included pyrexia, abdominal tenderness, and abdominal fullness.

Abscess location on CT scans was categorized into nine areas: right subphrenic, Subhepatic/Morson's pouch, right gutter, left subphrenic/perisplenic, left gutter, peripancreas/ lesser sac, pelvis/perirectal, below the abdominal wall, and other interperitoneal. A single abscess was defined as an abscess found in a single location, whereas multiple abscesses were defined as abscesses located in more than two locations. Duration in the cumulative success rate of PAD was defined as the interval between PAD puncture and complete resolution of the abscess.

Statistical analysis

Quantitative data are expressed as mean \pm SE (range). Comparisons between the success group and the failure group were analyzed by the Chi-square test with Yate's correction and the Mann-Whitney $U$ test for quantitative and qualitative variables, using Statview 4.5 software (Abacus Concepts, Berkeley, CA, USA). Univariate analysis was used to examine the relationship between the success of PAD and the variables studied. All variables associated with the failure group resulting in $p<0.1$ on univariate analysis were examined consecutively by multivariate analysis logistic regression. A $p$ value of $<0.05$ was considered significant. Correlation between the enteric fistulae and a single or late-onset abscess was analyzed by the Chi-square test with Yate's correction.

\section{Results}

Outcome after PAD for postoperative intra-abdominal abscess

The success rate of PAD at 1 year was $85.6 \%(n=89)$, although 24 of these patients required repeat drainage. The failure group consisted of six patients who underwent emergency operations for peritonitis, and nine patients who underwent or needed to undergo elective operations for enteric fistulae. Table 3 summarizes the clinical characteristics and outcomes of these 15 patients. Six patients required emergency conversion to open surgical drainage and stoma construction after PAD because of peritonitis originating from enteric fistulae. In eight patients, the enteric fistulae were not closed and elective surgery was 
Table 3 Clinical characteristics and outcome of the 15 patients in the failure group

\begin{tabular}{|c|c|c|c|c|c|c|}
\hline Case & Age & Gender & Types of primary disease & Procedure of restorative operation & $\begin{array}{l}\text { Emergency/ } \\
\text { Elective }\end{array}$ & $\begin{array}{l}\text { Intervals between initial } \\
\text { PAD and restorative } \\
\text { operation }\end{array}$ \\
\hline 1 & 19 & M & UC & $\begin{array}{l}\text { Open surgical drainage and stoma } \\
\text { construction }\end{array}$ & Emergency & 1 \\
\hline 2 & 22 & M & UC & $\begin{array}{l}\text { Open surgical drainage and stoma } \\
\text { construction }\end{array}$ & Emergency & 1 \\
\hline 3 & 25 & $\mathrm{~F}$ & UC & $\begin{array}{l}\text { Open surgical drainage and stoma } \\
\text { construction }\end{array}$ & Emergency & 1 \\
\hline 4 & 75 & $\mathrm{~F}$ & Colorectal cancer & $\begin{array}{l}\text { Open surgical drainage and stoma } \\
\text { construction }\end{array}$ & Emergency & 2 \\
\hline 5 & 91 & M & $\begin{array}{l}\text { Adhesive small bowel } \\
\text { obstruction }\end{array}$ & $\begin{array}{l}\text { Open surgical drainage and stoma } \\
\text { construction }\end{array}$ & Emergency & 2 \\
\hline 6 & 79 & M & Colorectal cancer & $\begin{array}{l}\text { Open surgical drainage and stoma } \\
\text { construction }\end{array}$ & Emergency & 5 \\
\hline 7 & 64 & M & Colorectal cancer & Reanastomosis without stoma construction & Elective & 32 \\
\hline 8 & 30 & M & $\mathrm{CD}$ & Stoma construction & Elective & 57 \\
\hline 9 & 32 & M & $\mathrm{CD}$ & $\begin{array}{l}\text { Reanastomosis with dysfunctional stoma } \\
\text { construction }\end{array}$ & Elective & 74 \\
\hline 10 & 38 & M & Gastric cancer & gastro-jejunal bypass & Elective & 88 \\
\hline 11 & 34 & M & $\mathrm{CD}$ & Stoma construction & Elective & 148 \\
\hline 12 & 25 & M & $\mathrm{UC}$ & Stoma construction & Elective & 171 \\
\hline 13 & 15 & $\mathrm{~F}$ & $\mathrm{CD}$ & Reanastomosis without stoma construction & Elective & 364 \\
\hline 14 & 37 & $\mathrm{~F}$ & $\mathrm{CD}$ & Reanastomosis without stoma construction & Elective & 720 \\
\hline $15^{\mathrm{a}}$ & 71 & $\mathrm{~F}$ & Colorectal cancer & - & - & - \\
\hline
\end{tabular}

$U C$ ulcerative colitis, $C D$ Crohn's disease, $P A D$ percutaneous abscess drainage

${ }^{a}$ Patients with persistent enteric fistulae for over 1 year

needed later. All enteric fistulae during PAD were confirmed by fluoroscopy. In one patient, the enteric fistula persisted for over 1 year and elective surgery was scheduled. All of the 'failure group' patients had enteric fistulae. No patient died after PAD in this series. There was one major complication related to PAD; namely, massive bleeding from long-term placement, in a patient from the success group.

Factors associated with successful outcome

Univariate analysis showed that a higher white blood cell count tended to be associated with successful PAD, but there were no other differences in patient- and surgeryrelated factors between the success and failure groups (Table 4). A longer interval between surgery and onset and having a single abscess were also associated with success, but there were no other differences in abscess- and drainage-related factors between the success and failure groups (Table 5). Multivariate analysis was performed using three variables (Table 6): white blood cell count, interval between surgery and onset, and single abscess. Multivariate analysis showed that a longer interval between surgery and onset (odds ratio $=1.248 ; 95 \%$ CI $1.031-1.510 ; p=0.0232)$ and having a single abscess (odds ratio $=7.690 ; 95 \%$ CI $1.899-31.136 ; p=0.0042$ ) were significantly associated with the successful outcome of PAD.

Success rates of PAD for patients with vs. those without factors related to outcome

The median interval between surgery and the onset of intraabdominal abscess was 8 days, the onset being early ( $<8$ days) in 55 patients and late ( $>9$ days) in 49 patients. Patients were divided into two groups according to the presence or absence of factors related to a successful outcome. Group A $(n=35)$ comprised patients with a single and late-onset abscesses and group B $(n=69)$ comprised patients with multiple and/or early onset abscesses. Figure 1 shows the cumulative success rates of PAD in Groups A and B. The success rate of PAD in Group A was $97.1 \%$ (34/35), with a median PAD period of 14 days and 
Table 4 Patient-related and surgery-related factors divided into success and failure groups

\begin{tabular}{|c|c|c|c|}
\hline Factors & Success group $(n=89)$ & Failure group $(n=15)$ & $p$ value \\
\hline Age at surgery (years) & $52 \pm 2$ & $44 \pm 6$ & 0.2116 \\
\hline Gender (M/F) & $61 / 28$ & $10 / 5$ & $>0.9999$ \\
\hline Malignant disease $(\mathrm{Y} / \mathrm{N})$ & $44 / 45$ & $6 / 9$ & 0.6910 \\
\hline Inflammatory bowel disease $(\mathrm{Y} / \mathrm{N})$ & $32 / 57$ & $9 / 6$ & 0.1396 \\
\hline Preoperative intra-abdominal abscess $(\mathrm{Y} / \mathrm{N})$ & $7 / 82$ & $3 / 12$ & 0.1403 \\
\hline Steroid treatment $(\mathrm{Y} / \mathrm{N})$ & $22 / 67$ & $4 / 11$ & $>0.9999$ \\
\hline Diabetes mellitus (Y/N) & $8 / 88$ & $0 / 15$ & 0.5987 \\
\hline White blood cell count $\left(/ \mathrm{mm}^{3}\right)$ & $12400 \pm 500$ & $11800 \pm 2400$ & 0.0663 \\
\hline Hemoglobin (g/dl) & $10.0 \pm 0.2$ & $10.4 \pm 0.5$ & 0.6206 \\
\hline CRP (mg/d) & $12.6 \pm 0.8$ & $15.0 \pm 2.3$ & 0.3548 \\
\hline ALB (g/dl) & $3.0 \pm 0.1$ & $2.9 \pm 0.1$ & 0.3222 \\
\hline Choline esterase $(\Delta \mathrm{pH})$ & $0.48 \pm 0.02$ & $0.50 \pm 0.06$ & 0.8464 \\
\hline Categories of surgical procedure (GAST/SB/APPY/COLO) & $17 / 25 / 4 / 43$ & $1 / 7 / 0 / 7$ & 0.3521 \\
\hline Stoma construction $(\mathrm{Y} / \mathrm{N})$ & $34 / 55$ & $2 / 13$ & 0.1142 \\
\hline Anastomotic operation $(\mathrm{Y} / \mathrm{N})$ & $73 / 16$ & $12 / 3$ & $>0.9999$ \\
\hline Surgical duration (min) & $272 \pm 13$ & $227 \pm 27$ & 0.1612 \\
\hline Operative blood loss (g) & $523 \pm 53$ & $360 \pm 110$ & 0.3920 \\
\hline Wound class $(\mathrm{CC} / \mathrm{CO} / \mathrm{D})$ & $66 / 13 / 10$ & $10 / 4 / 1$ & 0.4738 \\
\hline
\end{tabular}

GAST gastric surgery, $S B$ small bowel surgery, $A P P Y$ appendectomy, $C O L O$ colorectal surgery, $C C$ clean-contaminated operation, $C O$ contaminated operation, $D$ dirty/infected operation

Table 5 Abscess- and drainage-related factors divided into "success" and "failure" groups

\begin{tabular}{|c|c|c|c|}
\hline Factors & $\begin{array}{l}\text { Success group } \\
(n=89)\end{array}$ & $\begin{array}{l}\text { Failure group } \\
(n=15)\end{array}$ & $p$ value \\
\hline $\begin{array}{l}\text { Interval between surgery } \\
\text { and onset (days) }\end{array}$ & $10 \pm 1$ & $6 \pm 1$ & 0.0003 \\
\hline $\begin{array}{l}\text { Interval between onset and } \\
\text { PAD (days) }\end{array}$ & $3 \pm 0$ & $4 \pm 2$ & 0.1679 \\
\hline Size of abscess $(<5 \mathrm{~cm})$ & $23 / 66$ & $2 / 13$ & 0.4701 \\
\hline Single abscess $(\mathrm{Y} / \mathrm{N})$ & $63 / 26$ & $3 / 12$ & 0.0005 \\
\hline $\begin{array}{l}\text { Drainage procedure } \\
\text { (CT/US) }\end{array}$ & $73 / 16$ & $10 / 5$ & 0.9434 \\
\hline $\begin{array}{l}\text { Concomitant use of } \\
\text { antibiotics therapy }(\mathrm{Y} / \mathrm{N})\end{array}$ & $69 / 16$ & $4 / 2$ & 0.3064 \\
\hline $\begin{array}{l}\text { Duration of antibiotics } \\
\text { therapy (days) }\end{array}$ & $8 \pm 1$ & $7 \pm 2$ & 0.9268 \\
\hline Multiple drain $(\mathrm{Y} / \mathrm{N})$ & $24 / 65$ & $6 / 9$ & 0.4699 \\
\hline Number of drainage tube & $1.5 \pm 0.1$ & $1.6 \pm 0.2$ & 0.4762 \\
\hline Additional PAD (Y/N) & $19 / 70$ & $5 / 10$ & 0.4915 \\
\hline
\end{tabular}

$P A D$ percutaneous abscess drainage

complete resolution within 10 weeks (70 days) in $91.4 \%$ $(32 / 35)$ and sometime after 10 weeks in $5.7 \%(2 / 35)$. The success rate of PAD in Group B was $79.7 \%$ (55/69), with a median PAD period of 21 days and complete resolution within 10 weeks in $76.8 \%(53 / 69)$ and sometime after 10 weeks in $2.9 \%(2 / 69)$.
Table 6 Logistic regression analysis for factors associated with successful outcome

\begin{tabular}{llll}
\hline & $\begin{array}{l}\text { Odds } \\
\text { ratio }\end{array}$ & $95 \%$ CI & $p$ value \\
\hline White blood cell count $\left(/ \mathrm{mm}^{3}\right)$ & 1.038 & $0.916-1.175$ & 0.5605 \\
$\begin{array}{l}\text { Interval between surgery and } \\
\text { onset (days) }\end{array}$ & 1.248 & $1.031-1.510$ & 0.0232 \\
$\begin{array}{l}\text { Single abscess (Y/N) } \\
\text { ingle }\end{array}$ & 7.690 & $1.899-31.136$ & 0.0042 \\
\hline
\end{tabular}

Association between the absence of enteric fistulae and a single and late-onset abscess

All enteric fistulae were confirmed during PAD by fluoroscopy and detected in 53 patients $(51.0 \%)$. No significant correlation was found between the absence of enteric fistulae and a single and late-onset abscesses $(p=0.1660)$.

Success rate of PAD for patients with abscess related to an enteric fistula

The success rate of PAD among patients with an abscess related to enteric fistulae was $71.7 \%$ with no difference in outcome between small intestinal fistulae and large intestinal fistulae $(p=0.8036)$. Factor XIII concentrate was injected during drainage for five patients with an enteric fistula, resulting in success in four. The success rate of PAD was $92.9 \%(13 / 14)$ for patients with a single and late-onset abscess related to enteric fistulae but only 


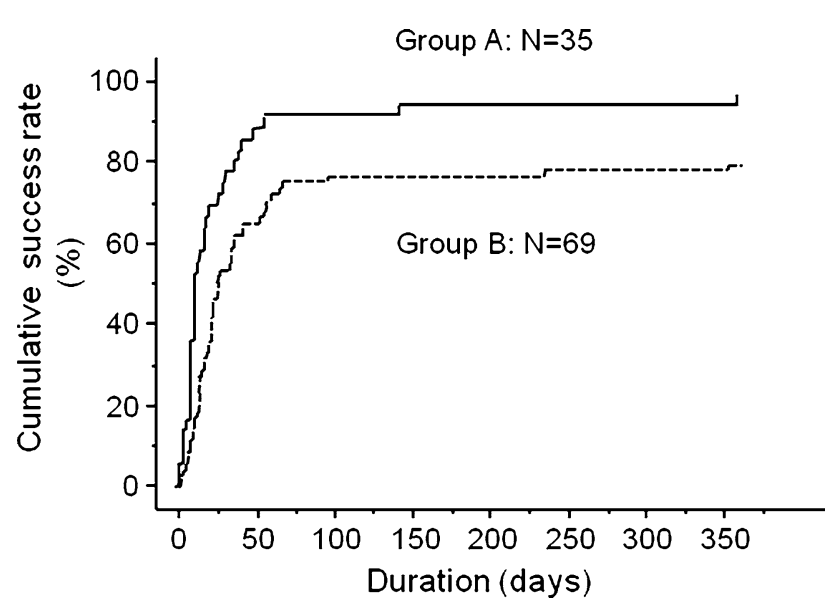

Fig. 1 The cumulative success rate of percutaneous abscess drainage in 104 patients increased with therapeutic duration. The success rate was $85.6 \%(n=89)$ after 1 year of follow-up

$64.1 \%(25 / 39)$ for patients with multiple and/or early onset-abscesses related to enteric fistulae.

\section{Discussion}

PAD was first described in the late 1970s and in 1981; Gerzof et al. [3] reported a success rate of $86 \%$ when used to treat intra-abdominal abscesses in 67 patients. Subsequently, it was demonstrated that the effectiveness and safety of PAD [8, 18-20], which over the last 30 years, made the transition from a revolutionary to a routine procedure, replacing open surgical drainage, except in the most difficult or inaccessible cases. Using univariate analysis, several authors have identified the factors predictive of the failure of PAD, including enteric fistulae, multiple or loculated abscesses, large abscesses, necrotic tissue, and pancreatic localization [3, 8, 11, 21-24].

Percutaneous drainage has been used in the management of complex abscesses, including multiple abscesses, those associated with fistulae, splenic abscesses, and infected fluid collections whose drainage route traversed normal organs) [7]. The use of PAD for patients with complex abscesses has been suggested to offer significant therapeutic benefits, even though it may not be curative and surgery could still be required [4, 25]. A study of the literature revealed a success rate of $45-88 \%$ for PAD treating complex abscesses [20, 26-28].

Some postoperative intra-abdominal abscesses associated with anastomotic leaks lead to diffuse peritonitis or abnormal communications between the gastrointestinal tract and the skin, with or without persistent clinical sepsis [29]. Approximately, one-third of enterocutaneous fistulae will close spontaneously with proper supportive care, control of sepsis, and nutritional support [30]. Wainstein et al. [31] reported that fistulae healed spontaneously in $46 \%$ of patients, within a mean period of 90 days (range 8-370 days). Peng et al. [32] reported that irrigationsuction through the drainage tubes was effective in approximately $75 \%$ of patients with leakage, without the need for surgical intervention. In their study, the median irrigation time when leakage occurred was 21 days (range 5-55 days). In the current study, the median interval between PAD puncture and complete resolution was 19 days (range 2-357 days). There are wide variations in the PAD period for postoperative intra-abdominal abscesses. The vast majority of studies on PAD for postoperative intra-abdominal abscesses have reported technical success based on short-term results, without long-term follow-up of individual patients, even though some had enteric communications [33-35]. However, long-term follow-up is necessary to accurately assess the complete resolution rate for postoperative intra-abdominal abscesses after PAD.

It has been reported that postoperative abscesses are significantly more likely than non-postoperative abscesses to be improved by PAD [36]. However, no published studies, except for that of Benoist et al., have analyzed patients who underwent PAD as the initial therapy for postoperative intra-abdominal abscesses, to find the factors predictive for success using multivariate regression analysis $[33,34,37]$. Benoist et al. examined the factors predictive of PAD failure for postoperative intra-abdominal abscesses in 73 patients and found that the absence of antibiotic therapy and an abscess diameter of $<5 \mathrm{~cm}$ were the only two independent factors associated with failure of PAD. These authors also showed that even complex postoperative abscesses, such as those associated with enteric fistulae, were not associated with failure. The overall success rate in the current study was $85.6 \%$ after 1 year of follow-up, which is consistent with the high success rates reported in previous studies [20, 26, 27, 37]. Multivariate analysis showed that a shorter interval between surgery and onset, and having multiple abscesses, but not the use of antibiotic therapy or the size of the abscess, were related to failure of PAD. Benoist et al. reported that patients with small abscesses in the failure group required repeat surgery for persistent or recurrent sepsis after drain removal, probably because of incomplete drainage. In our study, when abscess drainage was insufficient, the catheter was exchanged for a thicker one or it was moved to a position that allowed sufficient drainage. This adaptable drainage technique may have been an important factor in improving the outcome. Benoist et al. also reported that the absence of antibiotic therapy was an independent factor for failure of PAD. We did not give antibiotic therapy to patients with mild symptoms of an abscess; thus, the indications for antibiotic therapy may have been different in the two studies. No previous study has identified the interval 
between surgery and abscess onset as a significant predictive variable for failure of PAD. However, the early onset of postoperative intra-abdominal abscesses may reflect their severity.

In this study, the success rate of PAD was $78.0 \%$ (32/ 41 ) for patients with inflammatory bowel disease, whereas it was $90.5 \%(57 / 63)$ for those without inflammatory bowel disease ( $p=0.1396)$; however, inflammatory bowel disease was not related to the unsuccessful outcome statistically. Six of nine patients who underwent, or would undergo, elective surgery for an enteric fistula had inflammatory bowel disease. Moreover, the proportion of patients with inflammatory bowel disease needing elective surgery for an enteric fistula was $14.6 \%$ (6/41), whereas the proportion of patients without inflammatory bowel disease needing elective surgery for an enteric fistula was $4.8 \%(3 / 63)(p=0.1636)$. All in all, the proportion of patients with inflammatory bowel disease, who needed elective surgery for an enteric fistula, was not higher statistically.

We evaluated the rate of complete resolution within the first 10 weeks, and compared the median PAD periods in Groups A and B. The rate of complete resolution of single and late-onset abscesses within the first 10 weeks after PAD was very high. All of the patients with abscesses in the failure group also had enteric fistulae, demonstrating that enteric fistula was related to the unsuccessful outcome of PAD. There was no significant correlation between the absence of enteric fistulae and single and late-onset abscess, so single and late-onset abscesses did not indicate an absence of enteric fistulae. Even if abscesses related to enteric fistula were present, the success rate of PAD for single and late-onset abscesses was very high.

Enteric fistulas during PAD were detected in $51.0 \%$ of the patients in this study; however, the types of enteric fistula that tended to be cured by PAD were not analyzed. Campos et al. [38] and Gonzalez-Pinto et al. [39] reported that spontaneous closure was more likely for low-output fistulas, and those caused by surgery, those with free distal flow, healthy surrounding bowel, simple fistula with no associated abscess cavity, a fistula tract $>2 \mathrm{~cm}$, a fistula tract not epithelialized, an enteral defect $<1 \mathrm{~cm}$, a low fistula output, and no co-morbidity.

The potential limitations of our study include that it was a retrospective cohort series with a study population that was heterogeneous because of the wide variations in the disease and operative procedures. The decision of whether to employ PAD was at the discretion of the surgeon, which could have resulted in selection biases, and the data would be difficult to extrapolate to general patients undergoing gastrointestinal surgery. Multivariate logistic regression analysis was performed to minimize the effect of confounding factors. In addition, the effectiveness of conservative therapy such as nutritional management, the administration of octreotide and wound care, should be taken into consideration when examining factors that affect enteric fistulae closure. In this study, we focused on the relationship between patient-, surgery-, abscess- and drainage-related factors, and the outcome after PAD with long-term follow-up.

In conclusion, we evaluated the outcome of PAD in patients with intra-abdominal abscesses after recent gastrointestinal surgery. PAD is a safe and effective procedure for postoperative intra-abdominal abscess, with a high success rate and a low complication rate. We found that a single abscess and its late onset are independent predictors for a successful outcome of PAD. Conservative treatment within the first 10 weeks may be a better choice for patients with single and late-onset abscesses, even if persistent enteric fistulae are present. Initial recognition of the day of onset and the number of abscesses is important for providing prognostic information, which may subsequently influence the choice of treatment. Despite the establishment of modern strategies aimed at preventing surgical site infection, PAD remains an important factor in the postoperative management of gastrointestinal surgery in Japan. Further studies applying these prognostic models to different populations and larger numbers of patients are needed to validate and refine the models and generalize the results.

Conflict of interest Yoshiki Okita and his co-authors have no conflict of interest.

Open Access This article is distributed under the terms of the Creative Commons Attribution License which permits any use, distribution, and reproduction in any medium, provided the original author(s) and the source are credited.

\section{References}

1. Montgomery RS, Wilson SE. Intraabdominal abscesses: imageguided diagnosis and therapy. Clin Infect Dis. 1996;23:28-36.

2. Branum GD, Tyson GS, Branum MA, Meyers WC. Hepatic abscess. Changes in etiology, diagnosis, and management. Ann Surg. 1990;212:655-62.

3. Gerzof SG, Robbins AH, Johnson WC, Birkett DH, Nabseth DC. Percutaneous catheter drainage of abdominal abscesses: a fiveyear experience. N Engl J Med. 1981;305:653-7.

4. vanSonnenberg E, Wittich GR, Goodacre BW, Casola G, D'Agostino HB. Percutaneous abscess drainage: update. World J Surg 2001; 25:362-9; discussion 70-2.

5. Men S, Akhan O, Koroglu M. Percutaneous drainage of abdominal abcess. Eur J Radiol. 2002;43:204-18.

6. Harisinghani MG, Gervais DA, Hahn PF, Cho $\mathrm{CH}$, Jhaveri K, Varghese J, et al. CT-guided transgluteal drainage of deep pelvic abscesses: indications, technique, procedure-related complications, and clinical outcome. Radiographics. 2002;22:1353-67.

7. Golfieri R, Cappelli A. Computed tomography-guided percutaneous abscess drainage in coloproctology: review of the literature. Tech Coloproctol. 2007;11:197-208. 
8. Brolin RE, Nosher JL, Leiman S, Lee WS, Greco RS. Percutaneous catheter versus open surgical drainage in the treatment of abdominal abscesses. Am Surg. 1984;50:102-8.

9. Haaga JR. Imaging intraabdominal abscesses and nonoperative drainage procedures. World J Surg. 1990;14:204-9.

10. Johnson WC, Gerzof SG, Robbins AH, Nabseth DC. Treatment of abdominal abscesses: comparative evaluation of operative drainage versus percutaneous catheter drainage guided by computed tomography or ultrasound. Ann Surg. 1981;194:510-20.

11. Malangoni MA, Shumate CR, Thomas HA, Richardson JD. Factors influencing the treatment of intra-abdominal abscesses. Am J Surg. 1990;159:167-71.

12. Muller-Wille R, Iesalnieks I, Dornia C, Ott C, Jung EM, Friedrich $\mathrm{C}$, et al. Influence of percutaneous abscess drainage on severe postoperative septic complications in patients with Crohn's disease. Int J Colorectal Dis. 2011;26:769-74.

13. Inoue M, Uchida K, Otake K, Koike Y, Okugawa Y, Kobayashi $\mathrm{M}$, et al. Placement of prophylactic drains after laparotomy may increase infectious complications in neonates. Pediatr Surg Int. 2011;27:975-9.

14. Robinson JO. Surgical drainage: an historical perspective. Br J Surg. 1986;73:422-6.

15. Smith SR, Connolly JC, Crane PW, Gilmore OJ. The effect of surgical drainage materials on colonic healing. Br J Surg. 1982; 69:153-5.

16. Petrowsky H, Demartines N, Rousson V, Clavien PA. Evidencebased value of prophylactic drainage in gastrointestinal surgery: a systematic review and meta-analyses. Ann Surg. 2004;240: 1074-84; discussion 84-5.

17. Gaynes RP, Culver DH, Horan TC, Edwards JR, Richards C, Tolson JS. Surgical site infection (SSI) rates in the United States, 1992-1998: the National Nosocomial Infections Surveillance System basic SSI risk index. Clin Infect Dis. 2001;33(Suppl 2): S69-77.

18. Karlson KB, Martin EC, Fankuchen EI, Schultz RW, Casarella WJ. Percutaneous abscess drainage. Surg Gynecol Obstet. 1982; 154:44-8.

19. Martin EC, Karlson KB, Fankuchen EI, Cooperman A, Casarella WJ. Percutaneous drainage of postoperative intraabdominal abscesses. AJR Am J Roentgenol. 1982;138:13-5.

20. vanSonnenberg E, Ferrucci JT Jr, Mueller PR, Wittenberg J, Simeone JF. Percutaneous drainage of abscesses and fluid collections: technique, results, and applications. Radiology 1982; 142:1-10.

21. Bernini A, Spencer MP, Wong WD, Rothenberger DA, Madoff RD. Computed tomography-guided percutaneous abscess drainage in intestinal disease: factors associated with outcome. Dis Colon Rectum. 1997;40:1009-13.

22. Goletti O, Lippolis PV, Chiarugi M, Ghiselli G, De Negri F, Conte $\mathrm{M}$, et al. Percutaneous ultrasound-guided drainage of intraabdominal abscesses. Br J Surg. 1993;80:336-9.

23. Halasz NA, van Sonnenberg E. Drainage of intraabdominal abscesses. Tactics and choices. Am J Surg. 1983;146:112-5.
24. Lambiase RE, Deyoe L, Cronan JJ, Dorfman GS. Percutaneous drainage of 335 consecutive abscesses: results of primary drainage with 1-year follow-up. Radiology. 1992;184:167-79.

25. vanSonnenberg E, Wing VW, Casola G, Coons HG, Nakamoto SK, Mueller PR, et al. Temporizing effect of percutaneous drainage of complicated abscesses in critically ill patients. AJR Am J Roentgenol. 1984;142:821-6.

26. Schuster MR, Crummy AB, Wojtowycz MM, McDermott JC. Abdominal abscesses associated with enteric fistulas: percutaneous management. J Vasc Interv Radiol. 1992;3:359-63.

27. Wittich GR. Radiologic treatment of abdominal abscesses with fistulous communications. Curr Opin Radiol. 1992;4:110-5.

28. Gerzof SG, Johnson WC, Robbins AH, Nabseth DC. Expanded criteria for percutaneous abscess drainage. Arch Surg. 1985; 120:227-32.

29. Phitayakorn R, Delaney CP, Reynolds HL, Champagne BJ, Heriot AG, Neary P, et al. Standardized algorithms for management of anastomotic leaks and related abdominal and pelvic abscesses after colorectal surgery. World J Surg. 2008;32: 1147-56.

30. Schein M. What's new in postoperative enterocutaneous fistulas? World J Surg. 2008;32:336-8.

31. Wainstein DE, Fernandez E, Gonzalez D, Chara O, Berkowski D. Treatment of high-output enterocutaneous fistulas with a vacuumcompaction device. A ten-year experience. World J Surg. 2008; $32: 430-5$.

32. Peng J, Lu J, Xu Y, Guan Z, Wang M, Cai G, et al. Standardized pelvic drainage of anastomotic leaks following anterior resection without diversional stomas. Am J Surg. 2010;199:753-8.

33. Benoist S, Panis Y, Pannegeon V, Soyer P, Watrin T, Boudiaf M, et al. Can failure of percutaneous drainage of postoperative abdominal abscesses be predicted? Am J Surg. 2002;184:148-53.

34. Levison MA, Zeigler D. Correlation of APACHE II score, drainage technique and outcome in postoperative intra-abdominal abscess. Surg Gynecol Obstet. 1991;172:89-94.

35. Khurrum Baig M, Hua Zhao R, Batista O, Uriburu JP, Singh JJ, Weiss EG, et al. Percutaneous postoperative intra-abdominal abscess drainage after elective colorectal surgery. Tech Coloproctol 2002;6:159-64.

36. Cinat ME, Wilson SE, Din AM. Determinants for successful percutaneous image-guided drainage of intra-abdominal abscess. Arch Surg. 2002;137:845-9.

37. Bouali K, Magotteaux P, Jadot A, Saive C, Lombard R, Weerts J, et al. Percutaneous catheter drainage of abdominal abscess after abdominal surgery. Results in 121 cases. J Belge Radiol. 1993; 76:11-4.

38. Campos AC, Andrade DF, Campos GM, Matias JE, Coelho JC. A multivariate model to determine prognostic factors in gastrointestinal fistulas. J Am Coll Surg. 1999;188:483-90.

39. Gonzalez-Pinto I, Gonzalez EM. Optimising the treatment of upper gastrointestinal fistulae. Gut 2001;49(Suppl 4):iv22-iv31. 